\title{
Caracterização quali-quantitativa do fitoplâncton da zona de arrebentação de uma praia amazônica
}

\author{
Jislene Brito Matos ${ }^{1}$, Nayra Iris Sozinho da Silva ${ }^{2}$, Luci Cajueiro Carneiro Pereira ${ }^{2}$ e Rauquírio Marinho da Costa ${ }^{1,3}$
}

Recebido em 16/04/2012. Aceito em 8/08/2012

\begin{abstract}
RESUMO
(Caracterização quali-quantitativa do fitoplâncton da zona de arrebentação de uma praia amazônica). A estrutura da comunidade fitoplanctônica da praia da Princesa (Ilha de Maiandeua) foi estudada durante um ciclo nictemeral nos meses de novembro/08, março/09, junho/09 e setembro/09, de modo a verificar os efeitos de algumas variáveis ambientais sobre esta comunidade. O microfitoplâncton da praia da Princesa esteve representado por 98 táxons, com predomínio das diatomáceas, seguidas dos dinoflagelados e cianofíceas. Nas amostras qualitativas, Coscinodiscus perforatus Ehrenberg se destacou como abundante nos meses de março $(45,6 \%)$ e junho $(45,1 \%)$, enquanto que a análise quantitativa revelou Dimeregramma minor (Gregory) Ralfs como dominante, principalmente, em novembro (82,0\%) e setembro $(83,0 \%)$. A biomassa fitoplanctônica (clorofila-a) foi significativamente mais elevada em março $(U=0,0$; $\mathrm{p}<0,05)$. Os valores médios de densidade fitoplanctônica total foram significativamente mais elevados no período chuvoso $(\mathrm{F}=6,2 ; \mathrm{p}<0,05)$, principalmente em junho $\left(1223 \pm 110 \times 10^{3}\right.$ céls $\left.\mathrm{L}^{-1}\right)$. As curvas de $\mathrm{K}$-dominância revelaram um declínio gradual na diversidade ao longo do período seco. A análise de ordenação (MDS) evidenciou a formação de três grupos, enquanto que a análise de componentes principais (PCA) mostrou a salinidade e a turbidez como as principais variáveis que definiram os componentes. A praia da Princesa é um ambiente dinâmico, onde os processos de ressuspensão promovem o intercâmbio entre populações fitoplanctônicas e fitobênticas. A elevada precipitação e o maior aporte fluvial, carreando elevadas concentrações de nutrientes, favoreceram o maior desenvolvimento do fitoplâncton, principalmente, durante o período chuvoso.
\end{abstract}

Palavras-chave: Plâncton, Variáveis ambientais, Litoral Amazônico

\begin{abstract}
(Phytoplankton of the surf zone in Amazon beach). The structure of the phytoplankton community of Princesa beach (Maiandeua island) was investigated during a nyctemeral cycle in the months of November/08, March/09, June/09 and September/09 to verify the effects of certain environmental variables on this community. The microphytoplankton of Princesa beach was represented by 98 taxa with the dominance of the diatoms, which were followed by the dinoflagellates and cyanophytes. The qualitative study revealed that Coscinodiscus perforatus Ehrenberg was abundant in March (45.6\%) and June (45.1\%), whereas in the quantitative analysis Dimeregramma minor (Gregory) Ralfs was dominant, mainly in November/08 (82.0\%) and September/09 (83.0\%). Biomass (chlorophyll-a content) was significantly higher in March/08 $(\mathrm{U}=0.0 ; \mathrm{p}<0.05)$. The average total phytoplankton density was significantly higher during the rainy period $(\mathrm{F}=6.2 ; \mathrm{p}<0.05)$, mainly in June $\left(1,223 \pm 110 \times 10^{3}\right.$ cell $\left.\mathrm{L}^{-1}\right)$. $\mathrm{K}$-dominance curves showed a gradual decrease in diversity along the dry period. Non-Metric Multidimensional Scaling analysis (MDS) revealed the formation of three groups, whereas Principal Component Analysis (PCA) showed that salinity and turbidity were the main variables that defined the components. Princesa beach is a dynamic environment where ressuspension processes promote the shift between phytoplankton and phytobenthos populations. High rainfall and the increase in river runoff were responsible for an increase in nutrient availability contributing to the development of phytoplankton, mainly during the rainy period.
\end{abstract}

Key words: Plankton, Environmental variables, Amazon littoral

\footnotetext{
${ }^{1}$ Universidade Federal do Pará, Departamento de Biologia, Laboratório de Plâncton e Cultivo de Microalgas, Bragança, PA, Brasil

${ }^{2}$ Universidade Federal do Pará, Laboratório de Oceanografia Costeira, Bragança, PA, Brasil

${ }^{3}$ Autor para correspondência: raucosta@ufpa.br
} 


\section{Introdução}

O Brasil ocupa $47 \%$ da área total do continente da América do Sul e possui uma linha de costa de, aproximadamente, $8.500 \mathrm{~km}$ de extensão, das quais 35\% são ocupados pelo litoral amazônico brasileiro. Nesta região costeira estão inseridos diversos ambientes, como praias, planícies de marés, pântanos salinos e doces, estuários, manguezais, floresta de várzea, florestas tropicais, lagoas, lagunas, ilhas, rias, deltas, dunas, etc. (Glaser \& Diele 2004; Souza Filho et al. 2005; Pereira et al. 2009).

As ilhas costeiras são ecossistemas que se desenvolveram independente de outros ambientes, o que resultou em ambientes únicos com características específicas. Devido à sua formação e isolamento, esses ecossistemas apresentam grande diversidade biológica e alto grau de sensibilidade ambiental (Poletto \& Batista 2008).

Nesses ambientes, bem como em outros ecossistemas costeiros, a comunidade fitoplanctônica é extremamente importante, uma vez que contribui com a maior parte do carbono orgânico disponível para as cadeias alimentares pelágicas (Reynolds 2006). Os estudos sobre a biomassa fitoplanctônica e a composição das espécies pode fornecer um registro valioso da qualidade da água, além de gerar informações úteis para uma melhor compreensão de outros tipos de comunidades e ecossistemas em geral (Harris 1986). Neste contexto, o fitoplâncton tem provado ser um excelente indicador do estado trófico dos ecossistemas aquáticos e uma ferramenta útil na gestão ambiental das zonas costeiras (Hakanson 1994; Passavante \& Feitosa 2004).

Embora sejam de extrema importância para o conhecimento dos padrões espaciais e temporais da composição e da biomassa fitoplanctônica de ambientes costeiros, estudos na zona de arrebentação de praias arenosas na costa do estado do Pará são ainda incipientes, com estudos concentrados principalmente na praia de Ajuruteua, município de Bragança (Santana et al. 2005; Melo et al. 2005; Costa et al. 2011). Também são escassos estudos sobre fitoplâncton de zonas de arrebentação em ilhas amazônicas, com trabalhos realizados apenas na Ilha Canela, na desembocadura do estuário do Taperaçu (Sousa et al. 2008; 2009).

Portanto, com o intuito de ampliar os conhecimentos ecológicos sobre a comunidade fitoplanctônica em ambientes costeiros do Norte do Brasil, este trabalho representa o primeiro levantamento quali-quantitativo sobre o fitoplâncton da praia da Princesa (localizada na ilha de Maiandeua) e objetiva efetuar uma análise temporal da estrutura e biomassa desta comunidade e relacioná-las a alguns parâmetros ambientais locais.

\section{Material e métodos}

\section{Descrição da área de estudo}

A ilha de Maiandeua, subordinada ao município de Maracanã, corresponde a uma área de, aproximadamente, de
$23 \mathrm{~km}^{2}$ (Bastos 1988). A área de estudo está localizada na vila de Algodoal, na denominada praia da Princesa (Fig. 1), que possui, cerca de $14 \mathrm{~km}^{2}$ de extensão e é visitada por milhares de veranistas, inclusive estrangeiros, principalmente no mês de julho, feriados e festas de fim de ano (Sousa et al. 2011).

Na praia da Princesa, as alturas máximas de marés podem alcançar valores superiores a 5,8 m (marés equinociais de sizígia), sendo a mesma caracterizada por uma alta energia hidrodinânica em consequência das condições de macromarés que geralmente resultam em fortes correntes de maré, principalmente em períodos equinociais (Silva et al. 2011).

O clima local é equatorial úmido com temperatura anual elevada, típica de clima equatorial amazônico, com média de $26-27^{\circ} \mathrm{C}$, e precipitação anual em torno de $2.000 \mathrm{~mm}$, com duas nítidas estações sazonais, uma chuvosa de janeiro a junho e outra menos chuvosa de julho a dezembro (Martorano et al. 1993).

\section{Coleta e processamento dos dados}

Foram realizadas coletas hidrodinâmicas, hidrológicas e biológicas, em uma estação fixa (00³4,5’S e 47³5’ W) situada na praia da Princesa (Fig. 1B), durante os meses de novembro de 2008, março, junho e setembro de 2009. Amostragens nictemerais foram realizadas durante marés de sizígia, sendo as coletas hidrodinâmicas realizadas a cada 10 minutos, as hidrológicas a cada três horas e as biológicas em intervalos de seis horas.

Os dados referentes à pluviometria e ventos foram fornecidos pelo Instituto Nacional de Meteorologia (INMET) provenientes da estação meteorológica do município de Salinópolis, Pará (-0.618680 Lat. -47.3511 Long.) a aproximadamente, $27 \mathrm{~km}$ da área de estudo, a uma altura de $20 \mathrm{~m}$.

A direção e intensidade das correntes foram obtidas por meio de um mini-correntômetro (SENSORDATA SD6000), nos meses de março, junho e setembro/09 programado a processar leituras médias a cada 10 minutos. No mês de novembro/08, as perfilagens da velocidade e direção das correntes foram realizadas por um ADCP. Para determinar a altura (Hs) e período (Ts) das ondas utilizou-se um sensor TWR 2050 por meio do qual registrou-se valores médios a cada 10 minutos. Os equipamentos utilizados para determinar estas variáveis ficaram fundeados durante um período de $24 \mathrm{~h}$, a 1,7 $\mathrm{m}$ de profundidade.

A temperatura e salinidade foram medidas in situ com auxílio de um CTD (XR-420), enquanto que para as demais variáveis hidrológicas (oxigênio dissolvido, $\mathrm{pH}$, turbidez e nutrientes dissolvidos), bem como para determinação das concentrações de clorofila $a$, foram realizadas coletas sub-superficiais de água (0-1 m) com auxílio de uma garrafa de Niskin.

As amostras para o estudo qualitativo do microfitoplâncton foram coletadas através da filtragem de $400 \mathrm{~L}$ de água da camada sub-superficial da zona de arrebentação da praia utilizando uma rede de plâncton cônico-cilíndrica 


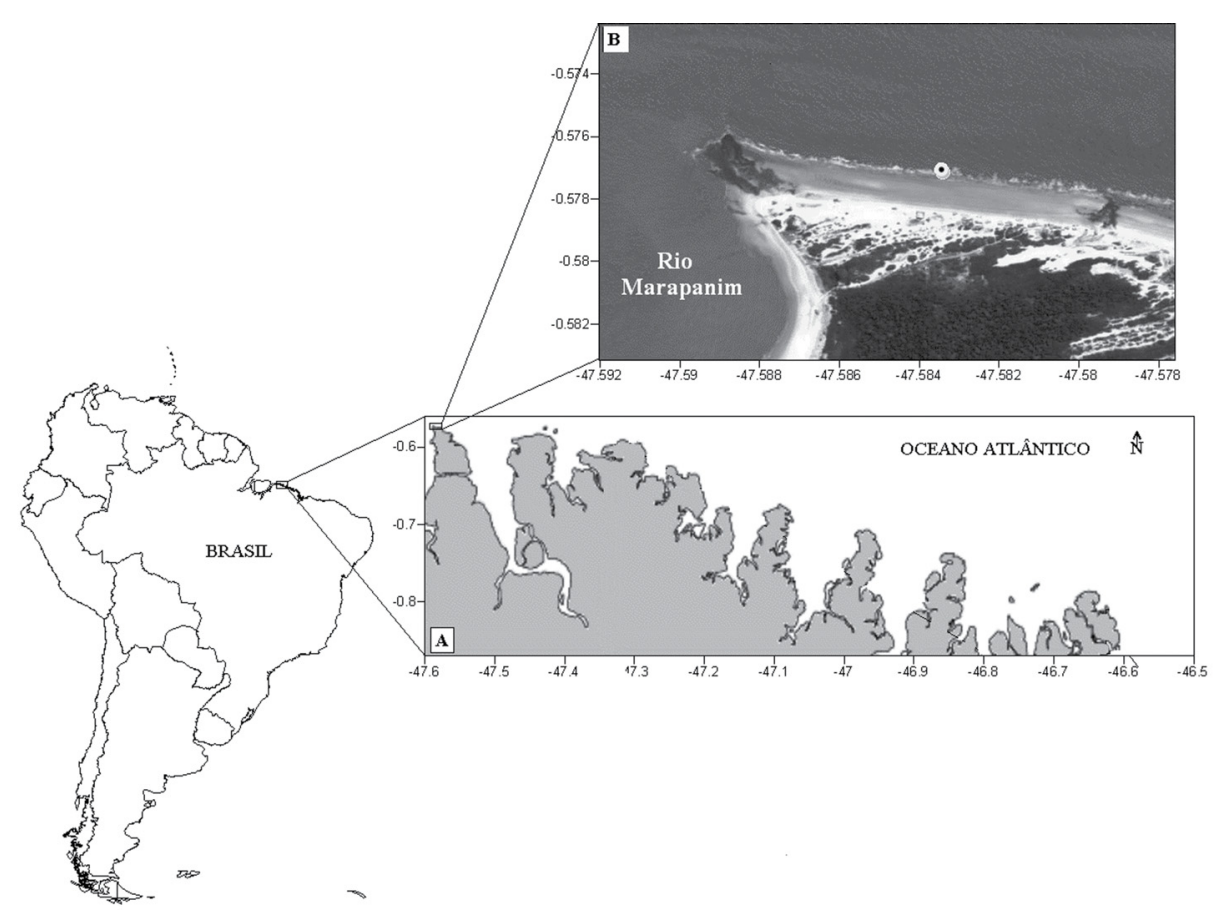

Figura 1. Mapa da área de estudo situada no nordeste do Pará (A): praia da Princesa (B) com localização da estação fixa de coleta (•), Ilha de Maiandeua, Pará, Brasil (Modificado de Sousa et al. 2011).

$(64 \mu \mathrm{m})$. O material coletado foi fixado com formalina $20 \%$ (concentração final de $4 \%-100 \mathrm{~mL}$ de formalina para $400 \mathrm{~mL}$ de água). As amostras destinadas aos estudos quantitativos do microfitoplâncton e do fitoplâncton total (fitoflagelados e microfitoplâncton somados) foram coletadas na subsuperfície da coluna d'água através de uma garrafa de Niskin, acondicionadas em recipientes plásticos (500 mL) devidamente etiquetados, sendo posteriormente preservadas em solução de Lugol.

No laboratório o $\mathrm{pH}$ foi medido com auxílio de um $\mathrm{pH}$ metro Labmeter PH2 (PHS-3B). Para a turbidez utilizou-se um turbidímetro Hanna (HI 39703), enquanto que para as concentrações de oxigênio dissolvido seguiu-se o método de Winkler modificado por Strickland \& Parsons (1972). Os nutrientes dissolvidos (nitrito, nitrato, fosfato e silicato) foram analisados de acordo com os métodos descritos por Strickland \& Parsons (1972) e Grasshoff et al. (1983), enquanto que as concentrações de clorofila-a foram determinadas espectrofotométricamente, segundo o método descrito por Parsons \& Strickland (1963).

A análise qualitativa do microfitoplâncton foi realizada através de montagens de lâmina-lamínula temporárias (contagem dos 100 primeiros indivíduos registrados), sendo observadas em microscópio binocular. Para cada amostra foram preparadas no mínimo cinco lâminas. Para a determinação da densidade fitoplanctônica (céls $\mathrm{L}^{-1}$ ) foi empregado método de sedimentação de Utermöhl (1958), realizando-se a contagem da área total da cubeta (volume de $7 \mathrm{~mL}$ ). Todas as amostras contadas foram previamente coradas com Rosa de Bengala (Throndsen 1978) e posteriormente analisadas em um invertoscópio, sob um aumento de 400 vezes. Os fitoflagelados foram identificados em nível de grupo.

Os critérios de classificação empregados na elaboração da composição florística foram Round et al. (1990) para as diatomáceas, Steindinger \& Tangen (1997 apud Tomas 1997) para os dinoflagelados e Desikachary (1959) para as cianobactérias. Os trabalhos de Moreira Filho et al. (1990) e Valente-Moreira et al. (1994) foram utilizados para o enquadramento ecológico das espécies identificadas. Todos os nomes científicos de espécies foram checados junto ao banco de dados internacional ITIS (Integrated Taxonomic Information System) e ALGAEBASE.

A frequência de ocorrência dos táxons foi calculada segundo Mateucci \& Colma (1982) tendo sido estabelecidas as seguintes categorias: muito frequente $(\geq 75 \%)$, frequente $(<75 \%$ e $\geq 50 \%)$, pouco frequente $(<50 \%$ e $\geq 25 \%)$ e esporádica $(<25 \%)$. Para a abundância relativa foram adotadas as seguintes categorias: dominante $(>70 \%)$, abundante $(\leq 70 \%$ e $>40 \%)$, pouco abundante $(\leq 40 \%$ e $>10 \%)$ e rara $(\leq 10 \%)$.

A partir dos dados obtidos na análise quantitativa estimou-se o índice de diversidade específica (Shannon 1948), sendo os resultados classificados segundo Margalef (1978),

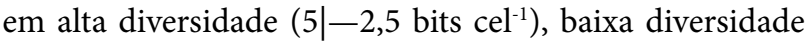
$\left(2,5 \mid-1\right.$ bit cel $\left.^{-1}\right)$ e diversidade muito baixa $\left(\leq 1\right.$ bit cel $\left.^{-1}\right)$. A equitabilidade foi determinada segundo Pielou (1977), com valores próximos a 0 indicando uma baixa equitabilidade, e valores próximos a 1 , uma alta equitabilidade.

Adicionalmente, para visualizar e comparar os perfis de diversidades em diferentes períodos sazonais e entre os meses de coletas, curvas de K-dominância foram plotadas, 
utizando o PRIMER 6.0 (Plymouth Routines Multivariate Ecological Research).

A partir dos valores obtidos das variáveis bióticas (densidade, diversidade, equitabilidade e clorofila-a) e abióticas (ondas, temperatura, salinidade, oxigenio dissolvido, $\mathrm{pH}$, turbidez e nutrientes dissolvidos) foram determinadas a normalidade (teste de Lilliefors) e homogeneidade das variâncias (teste de Bartlett) e quando necessário, os dados foram transformados $(\log x+1)$. As análises estatísticas incluíram a análise de variância (ANOVA - fator único), seguida pelo teste post-hoc de Fisher LSD (nível de significância de 5\%). Para dados não normais utilizou-se o teste não paramétrico de Mann-Whitney (U). Todas as análises foram efetuadas através do programa STATISTICA 6.0.

Análises multivariadas tais como, MDS (Análise de Ordenação) SIMPER (Percentual de Similaridade), ANOSIM (Análises de Similaridades) e PCA (Análise dos Componentes Principais) foram realizadas através do programa PRIMER 6.0. Para relacionar as variáveis abióticas e bióticas foi calculado o coeficiente de correlação de Spearman (r).

\section{Resultados}

\section{Variáveis climatológicas}

A precipitação pluviométrica total mensal durante o período de estudo oscilou entre 0,2 (novembro/08) e 412,9 $\mathrm{mm}$ (março/09). As velocidades dos ventos apresentaram intensidades médias variando de 1,4 $\pm 1,2 \mathrm{~m} \mathrm{~s}^{-1}$ (maio/09) a 4,4 $\pm 1,0 \mathrm{~m} \mathrm{~s}^{-1}$ (setembro/09) (Fig. 2).

Os ventos de nordeste (NE) predominaram durante os meses de estudo, entretanto, foram também observados nos meses chuvosos ventos vindos de sudeste (SE), sudoeste (SW) e noroeste (NW).

\section{Variáveis hidrodinâmicas}

Na praia da Princesa, as correntes de maré apresentaram direção predominantemente SE-NW na enchente e NW-SE, na vazante, com maiores intensidades observadas durante a enchente. Os meses de março/09 e setembro/09 apresentaram as intensidades mais elevadas (até $0,8 \mathrm{~m} \mathrm{~s}^{-1}$ ), enquanto em junho/09 foram registradas as intensidades mais baixas, com valores máximos atingindo $0,64 \mathrm{~m} \mathrm{~s}^{-1}$.

As alturas médias das ondas variaram de $0,5 \pm 0,2 \mathrm{~m} \mathrm{em}$ junho/09 a 0,7 $\pm 0,3 \mathrm{~m}$ em novembro/08, não apresentando diferenças sazonais e/ou mensais significativas. Os valores médios de período das ondas foram significativamente mais elevados no período chuvoso $(\mathrm{F}=5,4 ; \mathrm{p}<0,05)$, oscilaram entre 4,7 $\pm 1,5$ (setembro/09) e 6,1 $\pm 0,9$ seg (junho/09).

\section{Variáveis hidrológicas}

A temperatura da água na praia da Princesa variou de $27,9 \pm 0,3$ (setembro/09) a $28,6 \pm 0,5^{\circ} \mathrm{C}$ (novembro/08). Os valores médios de salinidade oscilaram entre $6,1 \pm 1,2$ (junho/09) e 34,5 $\pm 1,3$ (novembro/08) apresentando diferenças sazonais significativas com valores mais elevados no período seco $(\mathrm{U}=0,0 ; \mathrm{p}<0,05)$. A turbidez da água variou de 35,1 $\pm 16,7$ (novembro/08) a $105,1 \pm 25,4$ UNT (setembro/09), com valores significativamente mais elevados no mês de setembro/09 ( $\mathrm{F}=23,4 ; \mathrm{p}<0,05)$ (Fig. 3A).

As concentrações de oxigênio dissolvido na água apresentaram valores significativamente mais elevados no período seco $(\mathrm{F}=10,8 ; \mathrm{p}<0,05)$, oscilando entre $6,5 \pm$ 1,1 (março/09) e 7,8 $\pm 0,8 \mathrm{mg} \mathrm{L}^{-1}$ (setembro/09). O pH da água apresentou diferenças significativas entre os períodos sazonais com valores mais elevados no periodo seco $(\mathrm{F}=$ $86,3 ; \mathrm{p}<0,05)$, variando de $7,2 \pm 0,3$ (junho/09) a $8,2 \pm$ 0,1 (novembro/08) (Fig. 3B).

As concentrações médias de nitrito variaram de 0,1 $\pm 0,03$ (junho/09) a $0,3 \pm 0,1 \mu \mathrm{mol} \mathrm{L}^{-1}$ (setembro/09). O

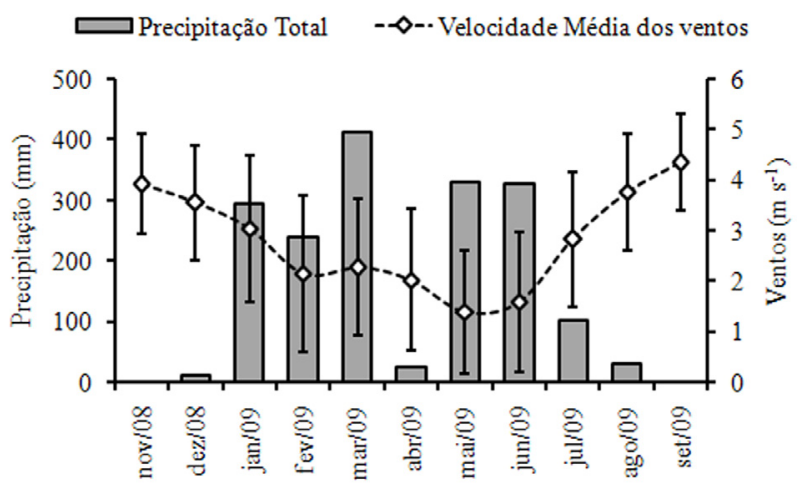

Figura 2. Variáveis climatológicas durante o período novembro/08 a setembro/09: Precipitação pluviométrica $(\mathrm{mm})$ e velocidade média dos ventos $\left(\mathrm{m} \mathrm{s}^{-1}\right)(\mathrm{D} . \mathrm{P} \pm$ ). Fonte: INMET (Estação Meteorológica do Município de Salinópolis-Pará).
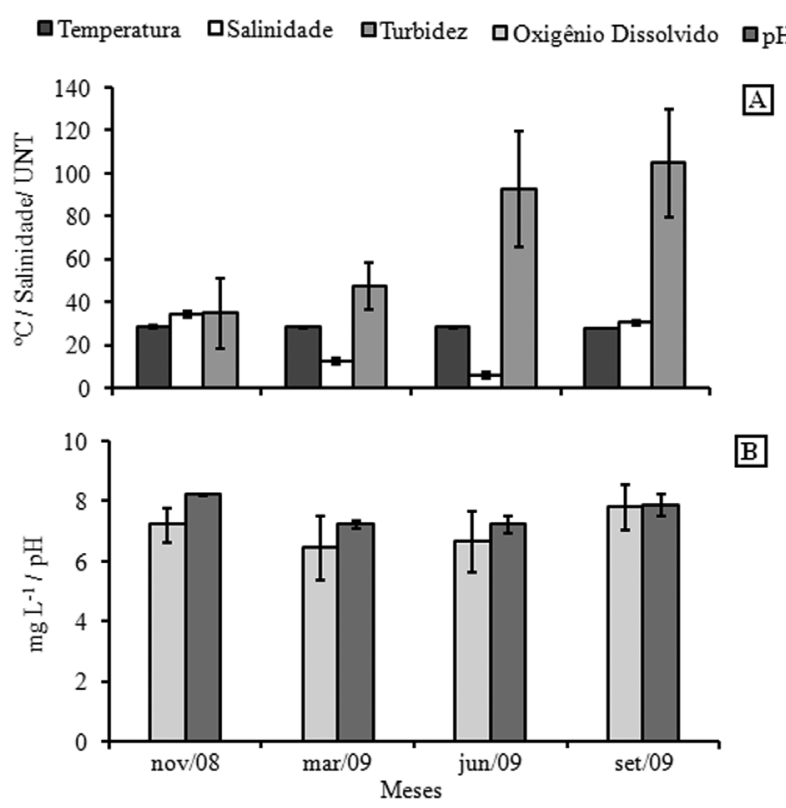

Figura 3. Variação média mensal ( \pm D.P.) dos parâmetros hidrológicos da praia da Princesa (Ilha de Maiandeua): A - Temperatura $\left({ }^{\circ} \mathrm{C}\right)$, salinidade, turbidez (UNT) e B - Oxigênio dissolvido $\left(\mathrm{mg} \mathrm{L}^{-1}\right)$ e $\mathrm{pH}$. 
nitrato apresentou concentrações médias oscilando entre $1,3 \pm 0,2$ (novembro/08) e 16,0 $\pm 8,8 \mu \mathrm{mol} \mathrm{L}^{-1}$ (março/09), com valores significativamente mais elevados no período chuvoso ( $U=76,0 ; p<0,05)$ (Fig. 4A).

$\mathrm{O}$ fosfato apresentou concentrações médias variando de $0,4 \pm 0,1$ (novembro/08) a $0,7 \pm 0,1 \mu \mathrm{mol} \mathrm{L}^{-1}$ (setembro/09), com valores significativamente mais elevados no mês de setembro $(U=17,0 ; p<0,05)$. As concentrações médias de silicato variaram de $28,1 \pm 8,5$ (novembro/08) a 293,9 $\pm 51,8 \mu \mathrm{mol} \mathrm{L}^{-1}$ (junho/09), com valores significativamente mais elevados durante o período chuvoso $(\mathrm{F}=10,6 ; \mathrm{p}<0,05)$ (Fig. 4B).

\section{Composição do microfitoplâncton}

A comunidade microfitoplanctônica da praia da Princesa esteve representada por 98 táxons, sendo destes 75 espécies e 23 morfo-espécies. Dentre as divisões, Bacillariophyta representou $90,8 \%$ dos táxons, sendo seguida por Dinophyta $(8,2 \%)$ e Cyanophyta (1,0\%).

As diatomáceas foram as mais representativas apresentando três classes, nove subclasses, 20 ordens e 32 famílias. Os gêneros predominantes foram Chaetoceros Ehrenberg e Coscinodiscus Ehrenberg, com nove táxons cada. Os dinoflagelados constituíram a segunda maior parcela do microfitoplâncton e foram representados pelas ordens Peridiniales (com duas famílias, Ceratiaceae e Protoperidiniaceae) e Prorocentrales (família Prorocentraceae). Já as cianobactérias foram representadas pela Família Oscillatoriaceae, com uma morfo-espécie.

Segundo a classificação ecológica das espécies, a maioria dos táxons pertence às categorias: ticoplanctônica (34,7\%) e nerítica (33,3\%). As demais categorias tiveram menor representatividade e correspenderam juntas a 32,0\%.

As espécies que estiveram em todas as amostras e se destacaram como muito frequentes foram Coscinodiscus centralis Ehrenberg, Coscinodiscus concinnus W. Smith, Coscinodiscus perforatus Ehrenberg, Dimeregramma minor (Gregory) Ralfs, Odontella mobiliensis (Bailey) Grunow e Odontella sinensis (Greville) Grunow.

Os valores de abundância relativa mostraram que a maioria das espécies foi considerada rara. Apenas a espécie Coscinodiscus perforatus se destacou como abundante nos meses de março/09 (45,6\%) e junho/09 (45,1\%). As espécies Coscinodiscus centralis (10,2\% em junho/09), C. concinnus (12,5\% em março/09), C. jonensianus (15,3\% em março/09), Dimeregramma minor (35\% em novembro/08) e Odontella sinensis $(10,1 \%$ em setembro/09) foram consideradas pouco abundantes (Fig. 5).

\section{Biomassa e densidade fitoplanctônica}

A biomassa fitoplanctônica, quantificada indiretamente através da clorofila-a, variou de 6,5 $\pm 2,0$ (junho/09) a 42,2 $\pm 13,3 \mathrm{mg} \mathrm{m}^{-3}$ (março/09) com valores significativamente mais elevados durante o mês de março/09 $(U=0,0 ; p<0,05)$ (Fig. 6).
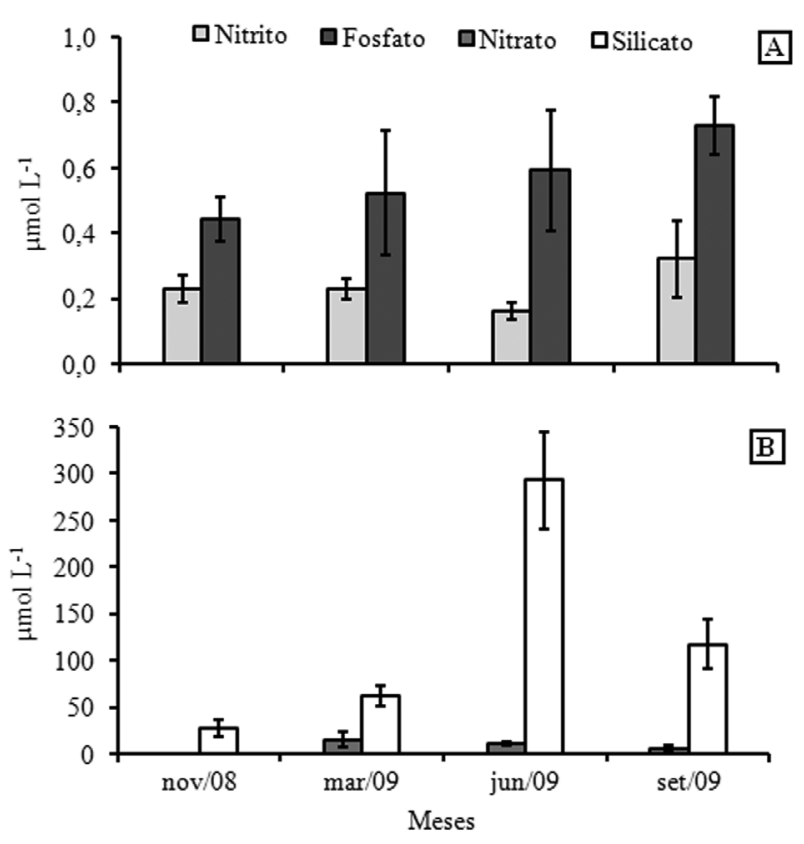

Figura 4. Variação média ( \pm D.P.) dos nutrientes dissolvidos da praia da Princesa (Ilha de Maiandeua): A - Nitrito e nitrato; B - Fosfato e silicato.

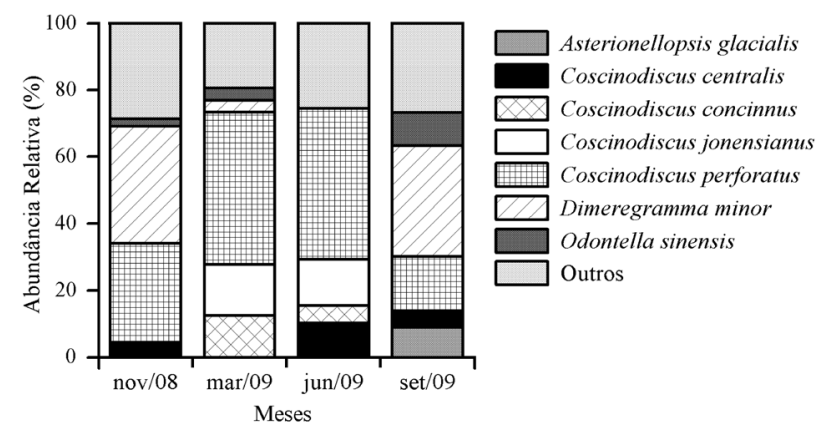

Figura 5. Abundância relativa mensal das principais espécies microfitoplanctônicas, na praia da Princesa, Ilha de Maiandeua, Pará.

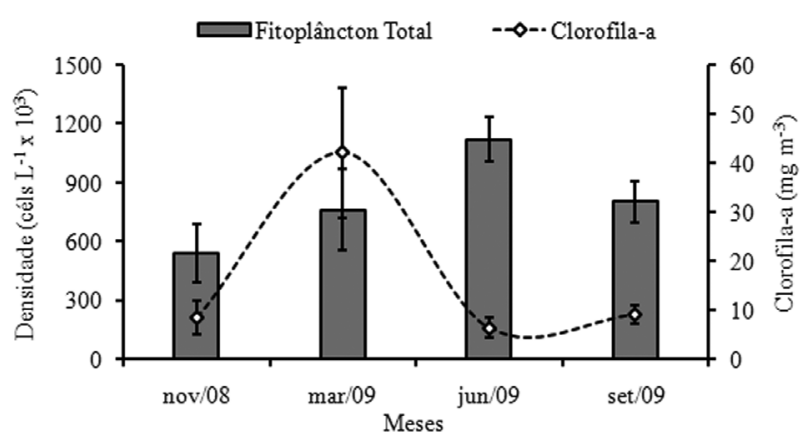

Figura 6. Variação média mensal ( \pm D.P.) da densidade fitoplanctônica total e biomassa fitoplanctônica (clorofila-a) da praia da Princesa, Ilha de Maiandeua, Pará. 
Os valores médios de densidade fitoplanctônica total variaram de $542 \pm 147 \times 10^{3}$ céls L $\mathrm{L}^{-1}$ (novembro/08) a 1223 $\pm 110 \times 10^{3}$ céls $\mathrm{L}^{-1}$ (junho/09), com valores significativamente mais elevados no período chuvoso $(\mathrm{F}=6,2 ; \mathrm{p}<0,05)$, principalmente em junho $(\mathrm{F}=10,5 ; \mathrm{p}<0,05)$ (Fig. 6).

A densidade média do microfitoplâncton variou de 281

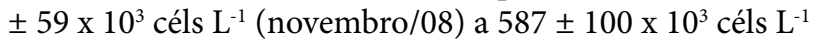
(setembro/09), com valores significativamente mais elevados em setembro/09 ( $\mathrm{F}=10,1 ; \mathrm{p}<0,05)$. Os fitoflagelados variaram de $217 \pm 13 \times 10^{3}$ céls L $^{-1}$ (setembro/09) a $592 \pm 47$ X

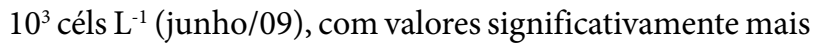
elevados no período chuvoso $(\mathrm{F}=25,6 ; \mathrm{p}<0,05)$ (Fig. 7A). Os fitoflagelados representaram até 53\% do fitoplâncton em junho/09, enquanto que o microfitoplâncton representou 73\% da comunidade em setembro/09 (Fig. 7B).

Os índices médios de diversidade ( $\left.\mathrm{H}^{\prime}\right)$ oscilaram entre $1,0 \pm 0,3$ (setembro/09) e 1,7 $\pm 0,3$ bits cél $^{-1}$ (março/09), apresentando valores significativamente mais elevados no período chuvoso $(\mathrm{F}=30,9, \mathrm{p}<0,05)$. O mesmo padrão sazonal (valores significativamente mais elevados no período chuvoso; $\mathrm{F}=27,5 ; \mathrm{p}<0,05)$ foi observado para a equitatilidade (J'), a qual variou de $0,2 \pm 0,04$ (setembro/09) a $0,4 \pm 0,1$ (março/09) (Fig. 8A). Os baixos valores de diversidade e equitabilidade, possivelmente, estão relacionados com a elevada contribuição de Dimeregramma minor ao longo do período de estudo (Fig. 8B).

As curvas de K-dominância ratificaram os padrões de diversidade e revelaram um declínio na de diversidade nos meses secos. As curvas durante esses meses (novembro e
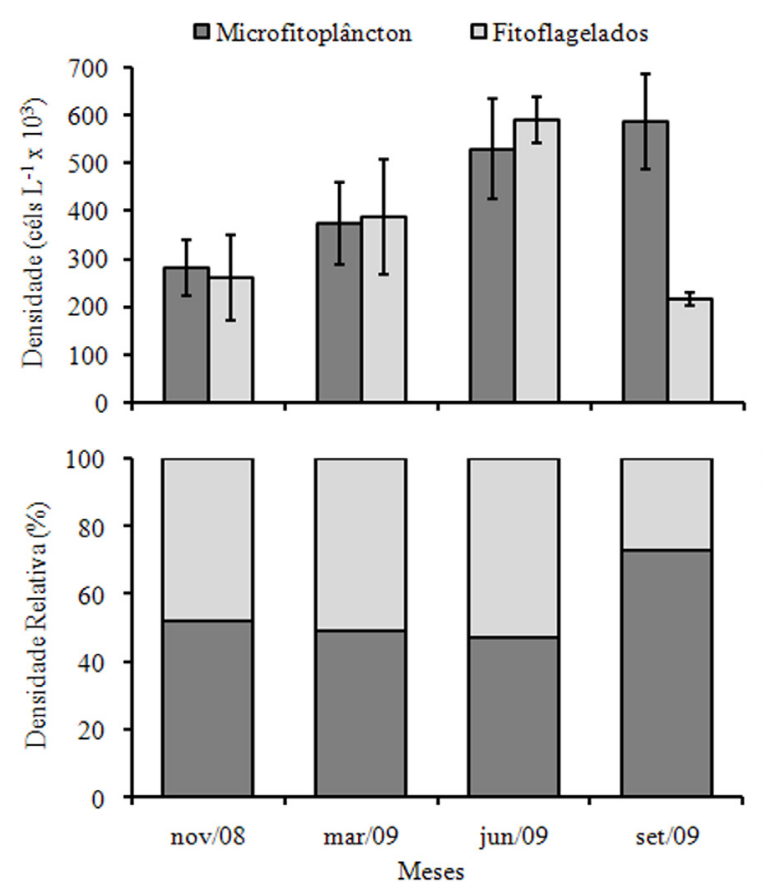

Figura 7. Variação média mensal ( \pm D.P.) da densidade do microfitoplâncton e dos fitoflagelados (A) e densidade relativa mensal do microfitoplâncton e dos fitoflagelados (B), na praia da Princesa, Ilha de Maiandeua, Pará. setembro) exibiram uma dominância mais elevada, porém menores diversidades. Um comportamento oposto aconteceu na estação chuvosa (Fig. 9A). As curvas de K-dominância ainda exibiram diferenças marcantes na diversidade e distribuições de densidades relativas de espécie entre os períodos sazonais (Fig. 9B).

\section{Análises Multivariadas}

A análise de ordenação (MDS) baseada na densidade das espécies fitoplanctônicas evidenciou a formação de três grupos, com stress de 0,15 (Fig. 10), revelando diferenças sazonais e temporais na estrutura da comunidade fitoplanctônica (ANOSIM R global= 0,$8 ; \mathrm{p}<0,05$ ).

O grupo 1 incluiu amostras do período chuvoso e uma amostra do mês de setembro/09, com dois subgrupos: $1 \mathrm{~A}$ e 1B. O subgrupo $1 \mathrm{~A}$ incluiu algumas amostras do mês de junho/09 (similaridade de 69,2\%), sendo Cyclotella menegheniana Kützing (SIMPER $(\mathrm{Sim} / \mathrm{SD})=13,4)$ a principal responsável para a formação deste subgrupo. O subgrupo $2 \mathrm{~A}$ reuniu a maioria das amostras do período chuvoso (similaridade de $72,9 \%$ ) e uma amostra de setembro. A espécie Melosira moniliformis (Müller) Agardh (SIMPER $(\mathrm{Sim} / \mathrm{SD})=14,7)$ foi a principal responsável pela formação deste subgrupo.

O grupo 2 reuniu amostras do mês setembro (similaridade 68,3\%), no qual a espécie Thalassionema nitzschoides Grunow (SIMPER $(\operatorname{Sim} / \mathrm{SD})=16,8)$ foi responsável pela formação deste grupo. $\mathrm{O}$ grupo 3 , incluiu as amostras do mês de novembro, com similaridade entre as amostras de

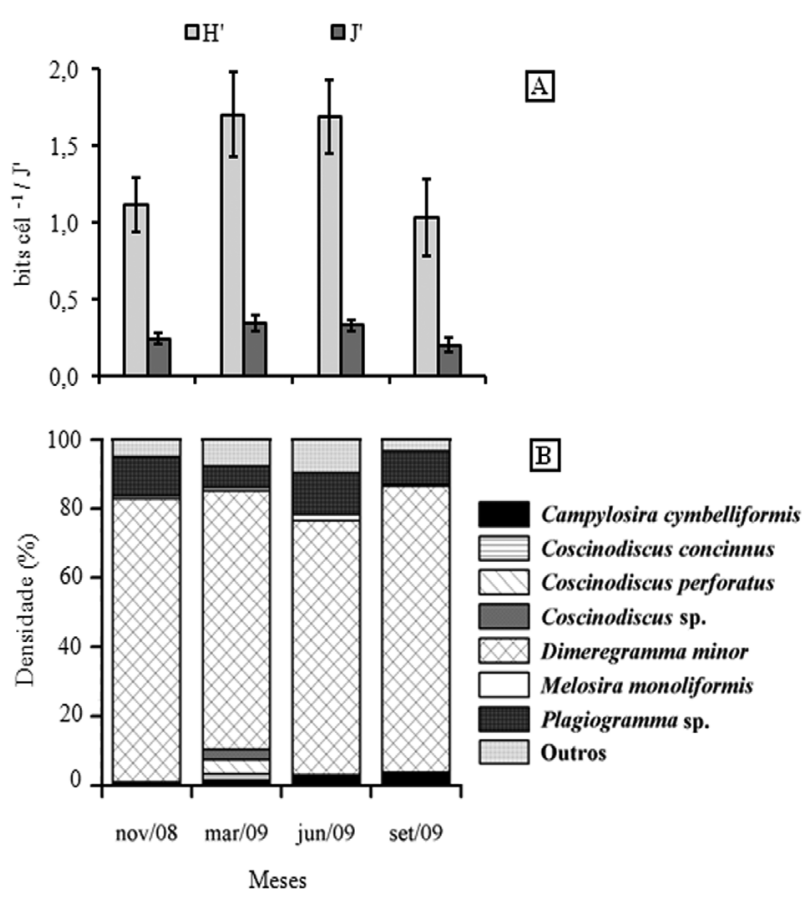

Figura 8. Variação média mensal (D.P.. dos índices de diversidade (H') e equitabilidade (J') das espécies $(\mathrm{A})$ relacionados à densidade relativa das principais espécies microfitoplanctônicas (B), na praia da Princesa, Ilha de Maiandeua, Pará. 

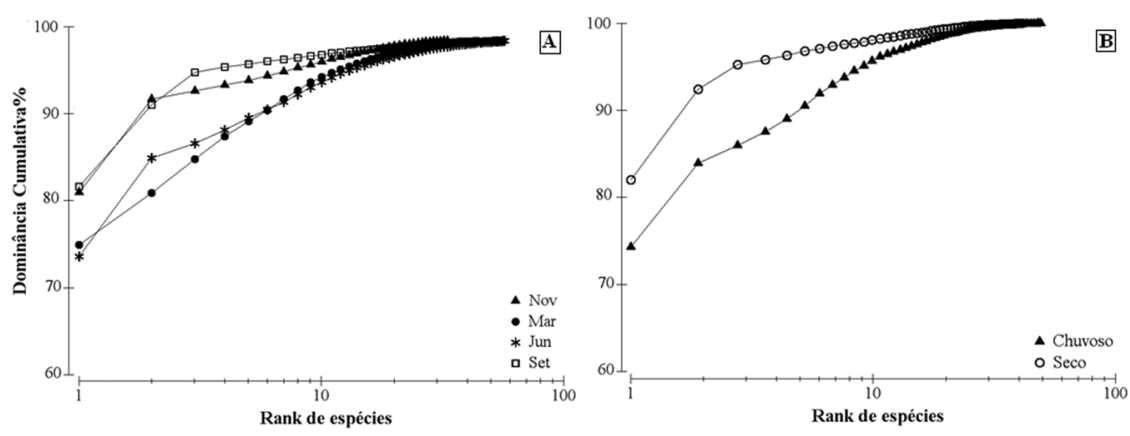

Figura 9. Curvas de dominância cumulativa das espécies microfitoplanctônica, ao longo dos diferentes meses (A) e períodos sazonais (B) na praia da Princesa, Ilha de Maiandeua, Pará.

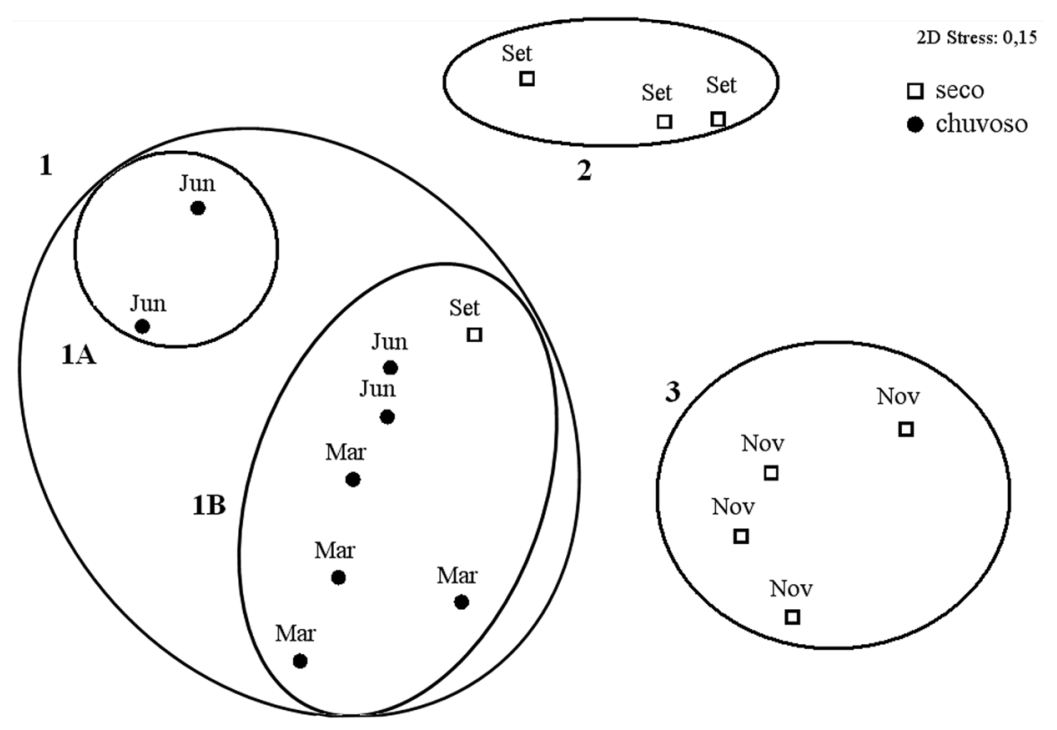

Figura 10. Análise de Ordenação (MDS) baseada na densidade das espécies microfitoplanctônicas, na praia da Princesa, Illha de Maiandeua, Pará.

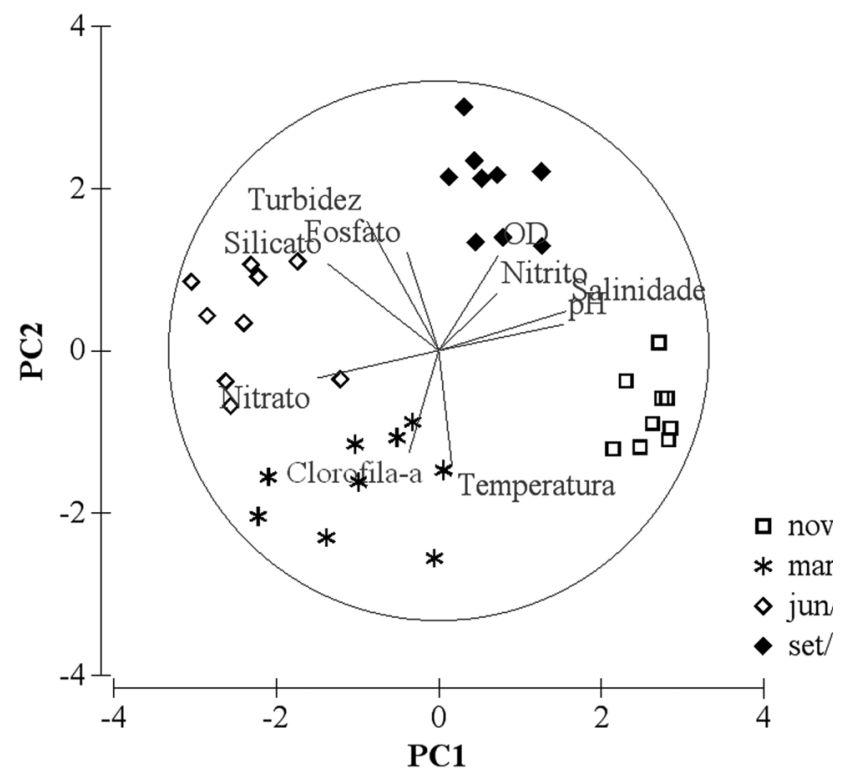

Figura 11. Análise de Componentes Principais para as variáveis ambientais, na praia da Princesa, Ilha de Maiandeua, Pará. 
$74,8 \%$, sendo a espécie Thalassiosira eccentrica (Ehrenberg) Cleve $(\operatorname{SIMPER}(\mathrm{Sim} / \mathrm{SD})=25,2)$ responsável pela formação do mesmo.

A análise de componentes principais - PCA (Fig. 11) mostrou que os dois primeiros componentes explicaram juntos $60 \%$ da variação dos dados. O componente 1 foi definido pela sazonalidade, uma vez que a salinidade (coeficiente: 0,47 ) separou os meses do período seco dos meses chuvosos. Este componente também se correlacionou positivamente com o oxigênio dissolvido (coeficiente: 0,22 ) e nitrito (coeficiente: 0,22 ), separando setembro dos demais meses pelas elevadas concentrações destas variáveis.

O componente 2 foi definido pela turbidez (coeficiente: 0,48 ), separando o mês de junho por apresentar águas mais turvas. Além disso, observou-se correlações positivas entre este segundo componente e os nutrientes dissolvidos fosfato (coeficiente: 0,36) e silicato (coeficiente: 0,32) e correlações negativas com a clorofila-a (coeficiente: $-0,38$ ), separando assim o mês de março/09 dos demais.

\section{Coeficiente de correlação de Spearman (r)}

As análises de correlação mostraram que as variáveis ambientais que mais se correlacionaram aos dados obtidos para a comunidade fitoplanctônica foram: salinidade, turbidez e nutrientes dissolvidos. A salinidade apresentou forte correlação negativa com a densidade total $(r=-0,8)$, fitoflagelados $(r=-0,8)$, diversidade $(r=-0,7)$ e equitabilidade $(r=-0,6)$. Quanto à turbidez, fortes correlações positivas foram observadas quando relacionada à densidade total $(r=0,6)$ e a densidade microfitoplanctônica $(r=$ $0,8)$. Os nutrientes dissolvidos também se correlacionaram fortemente com o fitoplâncton local: o nitrito apresentou uma correlação negativa com os fitoflagelados $(r=-0,6)$, o nitrato correlacionou-se positivamente com a diversidade $(r=0,6)$, o fosfato apresentou correlação positiva com o microfitoplâncton e silicato correlacionou-se positivamente à densidade total $(\mathrm{r}=0,9)$, microfitoplâncton $(\mathrm{r}=0,8)$ e fitoflagelados $(r=0,6)$.

\section{Discussão}

Na costa amazônica, o regime de macromarés, a grande quantidade de sedimentos carreados pelos rios para a costa e a alta hidrodinâmica em águas rasas favorece a ocorrência de praias com diferentes características (Rosa Filho et al. 2011). A praia da Princesa, localizada na porção norte da ilha de Maindeua, recebe influência direta do oceano Atlântico e a elevada energia hidrodinâmica local é consequência das condições de macromarés que, em geral, resultam em fortes correntes de maré (Beardsley et al. 1995).

Neste sentido, esta forte hidrodinâmica influenciada pelos movimentos gerados pelas ondas e marés aliadas aos fortes ventos e ao regime pluviométrico, alteram a dinâmica destas zonas costeiras. Além disso, nesses ambientes os elevados índices pluviométricos levam a um maior aporte fluvial, carreando nutrientes e materiais em suspensão, que influenciam diretamente o desenvolvimento do fitoplâncton (Sousa et al. 2009; Costa et al. 2011).

Em zonas de arrebentação, o regime de ventos tem sido apontado como um dos principais agentes mediadores das mudanças estruturais na comunidade fitoplanctônica, pelo processo de ressuspensão dos sedimentos de fundo (McLachlan 1980). Segundo Pedersen et al. (1995), a velocidade mínima dos ventos necessária para criar o revolvimento do fundo é estimada em $3 \mathrm{~m} \mathrm{~s}^{-1}$. Na praia da Princesa, os ventos mais intensos durante o mês de setembro $\left(4,4 \mathrm{~m} \mathrm{~s}^{-1}\right)$ juntamente com as condições de equinócio durante o referido mês, contribuíram para o aumento do número de células fitoplanctônicas na superfície da água através do processo de ressuspensão do sedimento e do empilhamento de células microalgais.

As ilhas costeiras possuem um complexo sistema de circulação de água resultante da interação de diversos fatores que agem de maneira particular em cada região, tais como as correntes de marés, os ventos, a influência das águas da drenagem continental, dos estuários, rios, manguezais e oceano adjacente. Estes fatores atuam em maior ou menor intensidade, gerando diferentes padrões de distribuição de salinidades, concentrações de oxigênio, $\mathrm{pH}$, nutrientes, entre outros (Paula et al. 1998; Grunnet et al. 2005).

No litoral amazônico, as condições climáticas associadas à presença de grandes rios e sistemas de manguezais, e as condições hidrodinâmicas únicas, são os principais fatores responsáveis pelas flutuações sazonais nas variáveis hidrológicas (Meade et al. 1985; Figueroa \& Nobre 1990; Marengo 1995; Geyer et al. 1996). Em geral, as águas costeiras amazônicas são eutróficas, alcalinas, turvas, bem oxigenadas e altamente produtivas (Santos et al. 2008; Costa et al. 2009; Magalhães et al. 2009; Sousa et al. 2009; Souza et al. 2009; Pereira et al. 2010).

Na praia da Princesa, as variáveis hidrológicas, em particular a salinidade, variaram consideravelmente entre os períodos sazonais. A salinidade é considerada um fator abiótico chave que regula a estrutura espacial e temporal da comunidade planctônica (Wooldridge 1999). Na costa amazônica, as variações de salinidade são comumente relacionadas às flutuações sazonais na precipitação, as quais exercem uma forte influência na dinâmica das comunidades fitoplanctônicas (Paiva et al. 2006; Sousa et al. 2008, 2009; Matos et al. 2011) por afetar diretamente outras variáveis ambientais importantes, tais como turbidez e disponibilidade de nutrientes (Smayda 1983).

A temperatura da água pode influenciar o metabolismo dos organismos fitoplanctônicos aumentando as taxas fotossintéticas e consequentemente, o crescimento e a reprodução destes organismos, como observado em algumas regiões temperadas (Philips et al. 2002). No entanto, a temperatura da água foi relativamente constante durante o período de estudo, outra característica típica de ambientes costeiros (Brugnoli-Olivera \& Morales-Ramírez, 2008) e em especial 
do litoral amazônico (Sousa et al. 2008; Matos et al. 2011; Sodré et al. 2011), onde a temperatura parece ter pouca influência sobre a estrutura e dinâmica destes organismos.

$\mathrm{Na}$ praia da Princesa, as concentrações de oxigênio dissolvido na água foram elevadas, apresentando uma significativa variação sazonal. Isto se deve, possivelmente, a rápida circulação decorrente da forte hidrodinâmica local que favorece a oxigenação da coluna d'água, como observado em outros ambientes costeiros rasos, turbulentos e com forte influência marinha (Campelo et al. 1999). Valores similares foram registrados em zona de arrebentação de outros ambientes da costa amazônica (Sousa et al. 2009; Costa et al. 2011), demonstrando assim o importante papel das trocas atmosfera-oceano sobre as concentrações de oxigenio dissolvido.

Segundo Flores Montes et al. (1998), a variação do pH é influenciada pelo ciclo de marés e pela taxa de fotossíntese e/ ou respiração. Quando a fotossíntese é a mais acentuada há um consumo de dióxido de carbono pelo fitoplâncton e os valores de $\mathrm{pH}$ acompanham o aumento de oxigênio liberado, porém no período de maior respiração ocorre o processo contrário. Desta forma, os dados de $\mathrm{pH}$ sugerem uma alta atividade fotossintética no local de estudo por apresentar geralmente valores alcalinos acompanhados de elevadas concentrações de oxigênio dissolvido. Não obstante, vale salientar que o principal mecanismo de manutenção dos valores de $\mathrm{pH}$ é o efeito tampão exercido pela água marinha, como observado para outros ecossistemas aquáticos da região amazônica (Costa et al. 2009; Sodré et al. 2011) e costa norte da Bahia, Brasil (Mafalda Jr et al. 2004).

No presente estudo, as águas foram mais turvas nos períodos de maior vazão fluvial (junho/09) e na maré equinocial de sizígia (setembro/09). Na costa amazônica, a elevada vazão dos rios e estuários aliada à elevada energia hidrodinâmica característica da região contribuem para que as águas costeiras sejam de elevada turbidez (Geyer et al. 1996; Pereira et al. 2009). Estes fatores reduzem a espessura da zona eufótica devido à rápida atenuação da energia luminosa, influenciando assim na absorção da luz pelo fitoplâncton (Azevedo et al. 2008). Não obstante, apesar da elevada turbidez observada no mês de junho e setembro, esses meses apresentaram as maiores densidades fitoplanctônicas, provavelmente em função das elevadas concentrações de nutrientes dissolvidos observados nos mesmos e/ou da ressuspensão de organismos do fitobentos (Sousa et al. 2009).

O nitrogênio, nas várias formas inorgânicas, é um dos principais elementos nutrientes que pode limitar a produção de matéria orgânica pelo fitoplâncton nos ecossistemas aquáticos, seguido pelo fósforo, na forma de fosfato (Tundisi \& Tundisi 1976). Além destes, as diatomáceas requerem ainda o silicato para a formação das frústulas. A disponibilidade desses nutrientes afeta diretamente a produtividade primária, biomassa e composição taxonômica do fitoplâncton, tendo como principais fontes as descargas fluviais e águas de drenagem terrestre provocadas pelas chuvas (Honorato da Silva et al. 2004). Na praia da Princesa, as maiores concentrações desses nutrientes ocorreram nos meses de junho e setembro, correspondendo aos maiores registros de densidade fitoplanctônica.

A composição e dinâmica da comunidade fitoplanctônica na praia da Princesa foi influenciada primariamente pelas variáveis hidrológicas. Dentre os grupos microalgais, as diatomáceas foram as principais responsáveis pela elevada riqueza taxonômica e abundância relativa na área em estudo. Estes organismos estão frequentemente associadas a regiões de frentes oceânicas caracterizadas por uma coluna de água turbulenta e sob efeito de correntes de alta velocidade (Reynolds 1997; Tilstone et al. 2000; Smayda 2002), sendo a predominância das mesmas referida para a maioria dos ambientes costeiros do nordeste paraense que sofrem forte influência marinha (Sousa et al. 2008; Santana et al. 2010; Costa et al. 2011; Matos et al. 2011; Sodré et al. 2011), bem como para outros ambientes do litoral brasileiro (Honorato da Silva et al. 2004; Azevedo et al. 2008; Villac et al. 2008).

A composição específica das diatomáceas esteve definida pela presença da espécie Dimeregramma minor, parecendo ser uma espécie típica da praia estudada, com registros em todos os períodos sazonais e com maior abundância durante o período seco, por se tratar de uma espécie polialóbia. Esta espécie tem sido frequentemente associada ao microfitobentos de ambientes costeiros arenosos rasos, onde contribui significativamente para produção primária (Cook \& Roy 2006; Hassan et al. 2006), sendo comumente encontrada em vários ambientes costeiros do litoral amazônico (Sousa et al. 2009; Costa et al. 2011; Matos et al. 2011). A presença de espécies ticoplanctônicas esteve associada ao regime de ventos, aliado às correntes de maré e a forte hidrodinâmica local, fazendo com que houvesse ressuspensão de sedimentos condicionando, desta maneira, o aparecimento de espécies bentônicas. As espécies planctônicas neríticas foram semelhantemente importantes, sendo sua contribuição comumente referida por outros autores para ambientes costeiros amazônicos, tais como a baía de Guajará (Paiva et al. 2006) e o estuário do Marapanim (Santana et al. 2010).

A biomassa fitoplanctônica (clorofila-a) foi significativamente mais elevada no mês de março (período chuvoso), visto que este período é marcado pelo início da estação chuvosa e a turbidez ainda não é muito elevada. Resultados similares tem sido registrados por diversos autores em regiões costeiras brasileiras (Grego et al. 2004; Sousa et al. 2008; Matos et al. 2011; Costa et al. 2011), demonstrando o efeito do início da estação chuvosa sobre a biomassa fitoplanctônica em função, possivelmente, da maior hidrodinâmica local e ressuspensão de nutrientes da coluna d'água. Segundo Eskinazi-Leça et al. (2004), este padrão de variação sazonal é característico de regiões costeiras tropicais onde a densidade do fitoplâncton aumenta durante o período chuvoso, estando na dependência do aporte de nutrientes carreados do continente. 
As densidades fitoplanctônicas sugeriram o mesmo padrão observado para biomassa e foram significativamente mais elevadas no período chuvoso, confirmando assim o padrão típico de ecossistemas costeiros que sofrem forte influência marinha (Honorato et al. 2004; Matos et al. 2011). Neste período sazonal, as condições ótimas para o florescimento do fitoplâncton são favorecidas, possivelmente, pelos nutrientes oriundos da lavagem dos manguezais pelas chuvas existentes nesta região, que enriquecem o ambiente e proporcionam o maior desenvolvimento desta comunidade.

Dentre os grupos fitoplanctônicos, os fitoflagelados foram quantitativamente mais representativos durante os meses chuvosos, padrão este descrito para outros ambientes amazônicos (Sousa et al. 2009; Costa et al. 2011). De acordo com Santos-Fernandes et al. (1998), a fração do nanoplâncton (fitoflagelados) é responsável pela maior parte da produtividade e clorofila dos ambientes costeiros, onde no mês de março foram registradas as concentrações de clorofila-a mais elevadas. Na praia da Princesa, os valores de densidade dos fitoflagelados estão de acordo com outros estudos realizados em diferentes ecossistemas aquáticos brasileiros (Koening et al. 2002; Melo et al. 2005).

Segundo Santander et al. (2003) em sistemas altamente dinâmicos, a adaptabilidade das espécies é um fator importante e por esta razão, diferentes conjuntos específicos da comunidade residente alcançaram índices elevados de crescimento em momentos também específicos. Assim, os padrões de distribuição temporal não seriam reflexo do conjunto da comunidade fitoplanctônica e sim, de certas populações que respondem a flutuações de determinados fatores ambientais. As curvas de K-dominância mostraram um declínio gradual nos valores de diversidade específica nos meses do período seco, em decorrência do domínio de uma ou poucas espécies (Omori \& Ikeda 1984). Os baixos valores de diversidades e equitabilidade registrados estiveram condicionados pela dominância da diatomácea Dimeregramma minor, principalmente durante o período seco, embora tenha ocorrido durante todo o período de estudo.

As análises multivariadas (MDS e PCA) demonstraram que os grupos formados foram separados primariamente por padrões sazonais, sendo influenciados principalmente pela salinidade, turbidez e nutrientes dissolvidos, em função dos diferentes indíces pluviométricos. As correlações ratificaram a influência destas variáveis hidrológicas sobre a comunidade fitoplanctônica, revelando a importante contribuição desses fatores como controladores da distribuição, abundância e dinâmica sazonal do fitoplâncton costeiro. Algumas espécies foram importantes na separação dos grupos encontrados no MDS (baseado na densidade fitoplanctônica), tais como Cyclotella menegheniana, Melosira moniliformis, Thalassionema nitzschoides e Thalassiosira eccentrica. Estas diatomáceas são comumente observadas em ambientes costeiros amazônicos (Costa et al. 2011; Matos et al. 2011) e algumas delas têm caracterizado a comunidade fitoplanctônica de ecossistemas costeiros com forte influência marinha no nordeste do Brasil (Lacerda et al. 2004).

A praia da Princesa, na ilha Maiandeua, é um ambiente dinâmico, onde os processos de ressuspensão provocados pelos ventos, arrebentação das ondas e correntes de maré causam a homogeneização da coluna d'água e promovem o intercâmbio entre populações planctônicas e ticoplanctônicas, alterando, em alguns períodos, a estrutura da comunidade fitoplanctônica local. Além disso, os elevados valores de precipitação e o maior aporte fluvial oriundo dos estuários adjacentes a esta ilha, e consequentemente os nutrientes carreados da lavagem dos manguezais, permitem o maior desenvolvimento do fitoplâncton principalmente durante o início do período chuvoso quando a transparência da água (baixa turbidez) ainda não constitui um fator limitante para o crescimento desses organismos.

\section{Agradecimentos}

A FAPESPA pelo financiamento dos projetos Universal (116/2008) e PROSGRAD (070/2008), aos quais o presente estudo esteve vinculado. Os autores agradecem ao $\mathrm{CNPq}$ pela concessão da bolsa de mestrado à primeira autora, pelo suporte financeiro oferecido através dos projetos CT-Hidro Casadinho (\# 552126/2005-5) e Taxonomia (\# 563967/05-6).

\section{Referências bibliográficas}

Azevedo, A.C.G. de; Feitosa, F.A.N. \& Koening, M.L. 2008. Distribuição espacial e temporal da biomassa fitoplanctônica e variáveis ambientais no Golfão Maranhense, Brasil. Acta Botanica Brasilica 22(3): 870-877.

Bastos, M.N.C. 1988. Levantamento florístico em restinga arenosa litorânea na Ilha de Maiandeua-Pará. Boletim do Museu Paraense Emílio Goeldi, Série Botânica 4(1): 159-176.

Beardsley, R.C.; Candela, J.; Limeburner, R.; Geyer, W.R.; Lentz, S.J.; Castro, B.M.; Cacchione, D. \& Carneiro, N. 1995. The M2 tide on the Amazon shelf. Journal of Geophysical Research 100(C2): 2283-2319.

Brugnoli-Olivera, E. \& Morales-Ramírez, A. 2008. Trophic planktonic dynamics in a tropical estuary, Gulf of Nicoya, Pacific coast of Costa Rica during El Niño 1997 event. Revista de Biología Marina y Oceanografía 43(1): 75-89.

Campelo, M.J.A.; Passavante, J.Z.O. \& Koening, M.L. 1999. Biomassa fitoplanctônica (clorofila $a$ ) e parâmetros ambientais na praia de Carne de Vaca, Goiana, Pernambuco, Brasil. Trabalhos Oceanográficos da Universidade Federal de Pernambuco 27(2): 27-41.

Cook, P.M.L. \& Roy, H. 2006. Advective relief of $\mathrm{CO}_{2}$ limitation in microphytobenthos in highly productive sandy sediments. Limnology and Oceanography 51(4): 1594-1601.

Costa, R.M. da; Leite, N.R. \& Pereira, L.C.C. 2009. Mesozooplankton of the Curuçá Estuary (Amazon Coast, Brazil). Journal of Coastal Research SI 56: 400-404.

Costa, V.B.; Sousa, E.B.; Pinheiro, S.C.C.; Pereira, L.C.C. \& Costa, R.M. da. 2011. Effects of a high energy coastal environment on the structure and dynamics of phytoplankton communities (Brazilian Amazon littoral). Journal of Coastal Research SI 64: 354-358.

Desikachary, T.S. 1959. Cyanophyta. New Delhi, Indian Council of Agricultural Researcher.

Eskinazi-Leça, E.; Koening, M.L. \& Silva-Cunha, M.G.G. 2004. Estrutura e dinâmica da comunidade fitoplanctônica. Pp. 353-373. In: E. Eskinazi-Leça; S. Neumann-Leitão; M.F. Costa (Orgs.). Oceanografia um cenário tropical. Recife, Universidade Federal de Pernambuco. 
Figueroa, S.N. \& Nobre, C.A. 1990. Precipitations distribution over Central and Western Tropical South América. Climanálise - Boletim de Monitoramento e Análise Climática 5(6): 36-45.

Flores Montes, M.J.; Macêdo, S.J.; Koening, M.L. \& Correia, I.L. 1998. Variação nictemeral do fitoplâncton e elemento nutrientes do Canal de Santa Cruz, Itamaracá-PE-Brasil. Trabalhos Oceanográficos da Universidade Federal de Pernambuco 26: 13-26.

Geyer, W.R.; Beardsley, R.C.; Lentz, S.J.; Candela, J.; Limeburner, R.; Johns, W.E.; Castro, B.M. \& Soares, I.D. 1996. Physical oceanography of the Amazon shelf. Continental Shelf Research 16: 575-616.

Glaser, M. \& Diele, K. 2004. Asymmetric outcomes: assessing central aspects of the biological, economic and social sustainability of a mangrove crab fishery, Ucides cordatus (Ocypodidade), in North Brazil. Ecological Economics 49: 361-373.

Grasshoff, K.; Emrhardt, M. \& Kremling, K. 1983. Methods of seawater analysis. New York, Verlag Chemie.

Grego, C.K.S.; Feitosa, F.A.N.; Honorato-da-Silva, M. \& Flores Montes, M.J. 2004. Distribuição espacial e sazonal da clorofila $a$ fitoplanctônica e hidrologia do estuário do rio Timbó (Paulista-PE). Tropical Oceanography 32: 135-236.

Grunnet, N.M.; Ruessink, B.G. \& Walstra, D.J.R. 2005. The influence of tides, wind and waves on the redistribution of nourished sediment at Terschelling, The Netherlands. Coastal Engineering 52: 617-631.

Hakanson, L. 1994. A review of effect-dose-sensitivity models for aquatic ecosystems. Internationale Revue der Gesamten Hydrobiologie und Hydrographie 79(4): 621-667.

Harris, G.P. 1986. Phytoplankton ecology: structure, function and fluctuation. London, Chapman \& Hall.

Hassan, G.S.; Espinosa, M.A. \& Isla, F.I. 2006. Modern diatom assemblages in surface sediments from estuarine systems in the southeastern Buenos Aires Province, Argentina. Journal of Paleolimnology 35: 39-53.

Honorato da Silva, M.; Passavante, J.Z.O.; Silva-Cunha, M.G.G.; Nascimento-Vieira, D.A.; Grego, C.K.S. \& Muniz, K. 2004. Distribuição espacial e sazonal da biomassa fitoplanctônica e dos parâmetros hidrológicos no estuário do rio Formoso (Rio Formoso, Pernambuco, Brasil). Tropical Oceanography 32: 89-106.

Koening, M.L.; Eskinazi-Leça, E. \& Neumann-Leitão, S. 2002. Impactos da construção do Porto de Suape sobre a comunidade fitoplanctônica no estuário do rio Ipojuca (Pernambuco-Brasil). Acta Botanica Brasilica 16: 407-420.

Lacerda, S.R.; Koening, M.L.; Neumann-Leitão, S. \& Flores-Montes, M.J. 2004. Phytoplankton nyctemeral variation at a tropical river estuary (Itamaracá-Pernambuco-Brazil). Brazilian Journal of Biology 64: 81-94.

Mafalda Jr., P.O.; Sinque, C.; Brito, R.R.C. de \& Santos, J.J. 2004. Biomassa planctônica, hidrografia e pluviosidade na costa norte da Bahia, Brasil. Tropical Oceanography 32(2): 143-158.

Magalhães, A.; Leite, N.R.; Silva, J.G.S.; Pereira, L.C.C., \& Costa, R.M. da. 2009. Seasonal variation in the copepod community structure from a tropical Amazon estuary, Northern Brazil. Annals of the Brazilian Academy of Sciences 81(2): 187-197.

Marengo, J. 1995. Interannual variability of deep convection in the tropical South American sector as deduced from ISCCP C2 data. International Journal Climatology 15(9): 995-1010.

Margalef, R. 1978. Les types biologiques de phytoplankton consideres comme des alternatives de survie dans um millieu instable. Oceanologica Acta 4(1): 493-509.

Martorano, L.G.; Perreira, L.C.; César, E.G.M. \& Pereira, I.C.B. 1993. Estudos climáticos do Estado do Pará, classificação climática (Köppen) e deficiência hídrica (Thornthwhite Mather). Belém, SUDAM/ EMBRAPA, SNLCS.

Mateucci, S.D. \& Colma, A. 1982. La metodología para el estudo de la vegetación. Collecion de Monografías Científicas, Série Biologia 22(1): 1-168.

Matos, J.B.; Sodré, D.K.L.; Costa, K.G.; Pereira, L.C.C. \& Costa, R.M. da. 2011. Spatial and temporal variation in the composition and biomass of phytoplankton in an Amazonian estuary. Journal of Coastal Research SI 64: 1525-1529.

McLachlan, A. 1980. The definition of sandy beaches in relation to exposure: a simple rating system. South African Journal of Science SI 76: $137-138$.
Meade, R.H.; Dune, T. \& Richey, J.E. 1985. Storage and remobilization of suspended sediment in the lower Amazon River of Brazil. Science 228: 488-490.

Melo, N.F.A.C.; Paiva, R.S. \& Silva, M.M.T. 2005.Variação diurna da densidade planctônica na região intertidal da praia de Ajuruteua (Bragança-Pará). Boletim do Museu Paraense Emílio Goeldi, Série Ciências Naturais 1(2): 153-180.

Moreira Filho, H.; Valente-Moreira, I.M.; Souza-Mosimann, R.M. \& Cunha, J.A. 1990. Avaliação florística e ecológica das diatomáceas (Chrysophyta, Bacillariophyceae) marinhas e estuarinas nos Estados do Paraná, Santa Catarina e Rio Grande do Sul. Estudos de Biologia 25: 5-48.

Omori, M. \& Ikeda, T. 1984. Methods in marine zooplanknton ecology. New York, J. Willey.

Paiva, R.S.; Eskinazi-Leça, E.; Passavante, J.Z. de O.; Silva-Cunha, M.G.G. \& Melo, N.F.A.C. 2006. Considerações ecológicas sobre a fitoplâncton da Baía do Guajará e Foz do Rio Guamá (Pará, Brasil). Boletim do Museu Paraense Emílio Goeldi, Série Ciências Naturais 1: 133-146.

Parsons, T.R. \& Strickland, J.D.H. 1963. Discussion of spectrophotometric determination of marine planckton pigments with revised equations of ascertaining clorophyll $a$ and carotenoids. Journal of Marine Research 21(3): 155-163.

Passavante, J.Z.O. \& Feitosa, F.A.N. 2004. Dinâmica da produtividade fitoplanctônica na Zona Costeira Marinha. Pp. 353-373. In: E. EskinaziLeça; S. Neumann-Leitão; M.F. Costa (Org.). Oceanografia - Um cenário tropical. Recife, UFPE.

Paula, J.; Pinto, I.; Guambe, I.; Monteiro, S.; Gove, D. \& Guerreiro, J. 1998. Seasonal cycle of planktonic communities at Inhaca Island, southern Mozambique. Journal of Plankton Research 20(11): 2165-2178.

Pedersen, O.B.; Christiansen, C. \& Lauren, M.B. 1995. Wind induced long term increase and short term fluctuations of shallow waters suspended matter and nutrient concentrations, Ringköbing Fjord, Denmark. Ophelia 41: 273-287.

Pereira, L.C.C.; Mendes, C.M.; Monteiro, M.C. \& Asp, N.E. 2009. Morphological and sedimentological changes in a macrotidal sand beach in the Amazon Littoral (Vila dos Pescadores, Pará, Brazil). Journal of Coastal Research SI 56: 113-117.

Pereira, L.C.C.; Monteiro, M.C.; Guimarães, D.O.; Matos, J. B. \& Costa, R.M. da, 2010. Seasonal effects of wastewater to the water quality of the Caeté river estuary, Brazilian Amazon. Annals of the Brazilian Academy of Sciences 82(2): 1-12.

Phlips, E.J.; Badylak, S. \& Grosskopf, T. 2002. Factors affecting the abundance of phytoplankton in a restricted subtropical lagoon, the Indian river lagoon, Flórida, USA. Estuarine, Coastal and Shelf Science 55: 385-402.

Pielou, E.C. 1977. Mathematical ecology. New York, Wiley.

Poletto, C.R.B. \& Batista, G.T. 2008. Sensibilidade ambiental das ilhas costeiras de Ubatuba, SP, Brasil. Ambi-Água 3(2): 106-121.

Reynolds, C.S. 1997. Vegetation processes in the pelagic: a model for ecosystem theory. Pp: 223-247. In: Kinne, O. (Ed.). Excellence in Ecology. Oldendorf, Ecology Institute Publisher.

Reynolds, C.S. 2006. Ecology of phytoplankton. Cambridge, Cambridge University Press.

Rosa Filho, J.S.; Gomes, T.P.; Almeida, M.F. \& Silva, R.F. 2011. Benthic fauna of macrotidal sandy beaches along a small-scale morphodynamic gradient on the Amazon coast (Algodoal Island, Brazil). Journal of Coastal Research SI 64: 435-439.

Round, F.E.; Crawford, R.M. \& Mann, D.G. 1990. The diatoms: biology and morphologia of the genera. New York, Cambrigde Universit Press.

Santana, D.S.; Paiva, R.S. \& Melo, N.F.A.C. 2005. Diatomáceas cêntricas da região entre marés da praia de Ajuruteua (Bragança - Pará). Boletim do Museu Paraense Emílio Goeldi, Série Ciências Naturais 1(2): 109-116.

Santana, D.S.; Paiva, R.S.; Pereira, L.C.C. \& Costa, R.M. da. 2010. Microphytoplankton of the Marapanim Estuary (Pará, Northern Brazil). Tropical Oceanography 38: 161-172.

Santander, E.; Herrera, L. \& Merino, C. 2003. Fluctuación diaria del fitoplancton en la capa superficial del océano durante la primavera de 1997 en el norte de Chile ( $\left.20^{\circ} 18^{\prime} \mathrm{S}\right)$ : II. Composición específica y abundancia cellular. Revista de Biología Marina y Oceanografía 38(1): 13-25. 
Santos, M.L.S.; Medeiros, C.; Muniz, M.; Feitosa, M.L.S.; Schwamborn, R. \& Macedo, S.J. 2008. Influence of the Amazon and Pará Rivers on water composition and phytoplankton biomass on the adjacent shelf. Journal of Coastal Research 24(3): 585-593.

Santos-Fernandes, T.L.; Passavante, J.Z.O.; Koening, M.L. \& Macêdo, S. J. 1998. Fitoplâncton do estuário do rio Jaguaribe (Itamaracá, Pernambuco, Brasil): Biomassa. Trabalhos Oceanográficos da Universidade Federal de Pernambuco 26: 1-18.

Shannon, C.E. 1948. A mathematical theory of communication. The Bell System Technical Journal 27: 379-423.

Silva, N.I.S.; Pereira, L.C.C.; Gorayeb, A.; Vila-Concejo, A.; Sousa, R.C.; Asp, N.E. \& Costa, R.M. da. 2011. Natural and social conditions of Princesa, a macrotidal sandy beach on the Amazon Coast of Brazil. Journal of Coastal Research SI 64: 1979-1983.

Smayda, T.J. 1983. The phytoplankton of estuaries. Pp. 65-102. In: B. H. Ketchum (ed.) Estuaries and enclosed seas - Ecosystems of the word. vol. 25. Amsterdan, Elsevier.

Smayda, T.J. 2002. Turbulence, watermass stratification and harmful algal bloms: an alternative view and frontal zones as "pelagic seed banks". Harmful Algae 1: 95-112.

Sodré, D.K.L.; Matos, J.B.; Costa, K.G.; Pereira, L.C.C. \& Costa, R.M. da. 2011. Tide-induced changes in the phytoplankton communities of three Amazon estuaries (Pará-Northern Brazil). Journal of Coastal Research SI 64: 1574- 1578.

Sousa, E.B.; Costa, V.B.; Pereira, L.C.C. \& Costa, R.M. da. 2008. Microfitoplâncton de águas costeiras amazônicas: Ilha Canela (Bragança, PA, Brasil). Acta Botanica Brasilica 22(3): 626-636.

Sousa, E.B.; Costa, V.B.; Pereira, L.C.C. \& Costa, R.M. da. 2009. Variação temporal do fitoplâncton e dos parâmetros hidrológicos da zona de arrebentação da Ilha Canela (Bragança, PA, Brasil). Acta Botanica Brasilica 23(4): 1084-1095.

Sousa, R.C. de; Pereira, L.C.C.; Silva, N.I.S.; Oliveira, S.M.; Pinto, K.S.T. \& Costa, R.M. da. 2011. Recreational carrying capacity of three Amazon macrotidal beaches during the peak vacation season. Journal of Coastal Research SI 64: 1292-1296.
Souza, L.R.; Zacardi, D.M.; Bittencourt, S.C.S.; Rawietsch, A.K.; Bezerra M.F.C.; Costa, S.D. \& Nakayama, L. 2009. Microalgas planctônicas de ocorrência nerítica e oceânica da costa do estado do Amapá-Brasil (PROGRAMA REVIZEE-SCORE NORTE III). Boletim TécnicoCientífico do CEPENOR 9: 115-124.

Souza Filho, P.W.M.; Cunha, E.R.S.P. da.; Sales, M.E.C.; Souza, L.F.M.O \& Costa, F.R. da. 2005. Bibliografia da Zona Costeira Amazônica. Belém, Museu Paraense Emílio Goeldi, Universidade Federal do Pará, Petrobrás.

Strickland, J.D.H. \& Parsons, T.R. 1972. A practical handbook of seawater analysis. 2 Ed. Bulletin Fisheries Research Board of Canada 167: 1-211.

Throndsen, J. 1978. Preservation and storage: Monographs on oceanographic methodology. Pp 69-74. In: Sournia, A. (Ed.). Phytoplakton manual. Norwich. Unesco.

Tilstone, G.H.; Míguez, B.M.; Figueiras, F.G. \& Fermín, E.G. 2000. Diatom dynamics in a coastal ecosystem affected by upwelling: coupling between species succession, circulation and biogeochemical processes. Marine Ecology Progress Series 205: 23-41.

Tomas, C.R. 1997. Identifying marine diatoms and dinoflagellates. San Diego. Academic Press. 598p.

Tundisi, J.G. \& Tundisi, T.M. 1976. Produção orgânica em ecossistemas aquáticos. Ciência e Cultura 38 (8): 864-867.

Utermöhl H. 1958. Zur vervolkommung der quantitativen phytoplankton - methodik. Mitteilungen Internationale Vereiningung fuer Theoretische und Angewandte Limnologie 9:1-38.

Valente-Moreira, I.M.; Moreira Filho, H. \& Cunha, J.A. 1994. Diatomáceas (Chrysophyta, Bacillariophyceae) em biótopo de manguezal do rio Perequê, em Pontal do Sul, Paranaguá, Estado do Paraná, Brasil. Acta Biologica Paranaense 23(1, 2, 3, 4): 55-72.

Villac, M.C.; Cabral-Noronha, V.A. de P. \& Pinto, T. de O. 2008. The phytoplankton biodiversity of the coast of the state of São Paulo, Brazil. Biota Neotropica 8(3): 151-173.

Wooldridge, T.H. 1999. Estuarine zooplankton community structure and dynamics. Pp. 141-166. In: B.R. Allanson \& D. BAIRD (eds.). Estuaries of South Africa. Cambridge, Cambridge University Press. 